\title{
Environmental Filtering Process Has More Important Roles than Dispersal Limitation in Shaping Large-Scale Prokaryotic Beta Diversity Patterns of Grassland Soils
}

\author{
Peng Cao ${ }^{1,2} \cdot$ Jun-Tao Wang ${ }^{1}$ Hang-Wei Hu ${ }^{3} \cdot$ Yuan-Ming Zheng ${ }^{1} \cdot$ Yuan $_{\text {Ge }}{ }^{1}$. \\ Ju-Pei Shen ${ }^{1} \cdot$ Ji-Zheng He ${ }^{1,3}$
}

Received: 4 January 2016 / Accepted: 28 March 2016 / Published online: 12 April 2016

(C) Springer Science+Business Media New York 2016

\begin{abstract}
Despite the utmost importance of microorganisms in maintaining ecosystem functioning and their ubiquitous distribution, our knowledge of the large-scale pattern of microbial diversity is limited, particularly in grassland soils. In this study, the microbial communities of 99 soil samples spanning over $3000 \mathrm{~km}$ across grassland ecosystems in northern China were investigated using high-throughput sequencing to analyze the beta diversity pattern and the underlying ecological processes. The microbial communities were dominated by Proteobacteria, Actinobacteria, Acidobacteria, Chloroflexi, and Planctomycetes across all the soil samples. Spearman's correlation analysis indicated that climatic factors and soil $\mathrm{pH}$ were significantly correlated with the dominant microbial taxa, while soil microbial richness was positively linked to annual precipitation. The environmental divergence-dissimilarity relationship was significantly positive, suggesting the importance of environmental filtering processes in shaping
\end{abstract}

Electronic supplementary material The online version of this article (doi:10.1007/s00248-016-0762-4) contains supplementary material, which is available to authorized users.

Ju-Pei Shen

jpshen@rcees.ac.cn

$\triangle$ Ji-Zheng $\mathrm{He}$

jzhe@rcees.ac.cn

1 State Key Laboratory of Urban and Regional Ecology, Research Center for Eco-Environmental Sciences, Chinese Academy of Sciences, Beijing 100085, China

2 Key Laboratory of Vertebrate Evolution and Human Origins of Chinese Academy of Sciences, Institute of Vertebrate Paleontology and Paleoanthropology, Chinese Academy of Sciences, Beijing 100044, China

3 Faculty of Veterinary and Agricultural Sciences, The University of Melbourne, Parkville, Victoria 3010, Australia soil microbial communities. Structural equation modeling found that the deterministic process played a more important role than the stochastic process on the pattern of soil microbial beta diversity, which supported the predictions of niche theory. Partial mantel test analysis have showed that the contribution of independent environmental variables has a significant effect on beta diversity, while independent spatial distance has no such relationship, confirming that the deterministic process was dominant in structuring soil microbial communities. Overall, environmental filtering process has more important roles than dispersal limitation in shaping microbial beta diversity patterns in the grassland soils.

Keywords Beta diversity · Richness · Dispersal limitation · Environmental filtering $\cdot$ Grassland $\cdot$ Soil microbial communities

\section{Introduction}

The unveiling of biodiversity patterns and their underlying mechanisms has long been a central objective for ecologists and biogeographers [1]. Over recent decades, mounting efforts have been directed to understanding the patterns of species richness at local (alpha-diversity) and/or regional scales (gammadiversity) [2-4]. However, beta diversity, which characterizes the turnover of species to describe the change of community compositions across two or more sites, is less studied $[1,5,6]$. Beta diversity, varying heterogeneously across ecosystems, can be a potential indicator for describing the dissimilarity of community structure. Although several patterns of beta diversity have been documented, they were mostly focused on plants or animals. For example, the similarity in composition of local assemblages, such as non-volant mammals, tropical forests, and vascular plants, was found to increase with increasing 
latitude [7-10]. Species turnover of amphibians and birds was strongly influenced by the environment mediated by range sizes and regional history [11]. Moreover, climatic gradient, topographic complexity, geographic variation (from gradual changes to abrupt transitions), ecological interactions, and biogeographic history (including dispersal barriers) can also have important roles in shaping beta diversity of macroorganisms [12-16]. However, the pattern of beta diversity of microorganisms is still scant, although several recent researches have examined the microbial beta diversity of some soils [17-20].

Understanding the pattern of beta diversity and clarifying the relative importance of ecological processes (for example, dispersal limitation versus environmental filtering), in shaping the community structure, is the central goal of the study of ecological community and biodiversity $[12,21]$. Ecological processes explaining the changes in community compositions can be generally grouped into two broad classes, stochastic and deterministic processes [22-24]. Dispersal limitation is a typical stochastic process which could significantly impact the community structure and has been used to explain the specific decay of the species similarity with increasing geographic distance [22, 23] (Fig. 1a). In contrast, the deterministic process is characterized by environmental filtering, which suggests that the species with similar traits tend to exist in the same habitat, and this process is governed by the divergence of environmental conditions [25]. Previous studies suggested that species similarity has a negative relationship with environmental heterogeneity according to the deterministic process as shown in Fig. 1b [25]. In other words, the habitat specialization resulting from adaptive evolution has a crucial role in determining community composition [26, 27], which is a typical deterministic process driven by environmental heterogeneity. Although stochastic and deterministic processes have been extensively documented in macroorganisms such as plants and animals, such studies in microbial communities and the relative importance of the two processes in regulating the distributions of microorganisms until recently received limited attention [17, 28-31].
Prokaryotes (including bacteria and archaea) play important roles in the global nutrient cycling, ecosystem services, and environmental sustainability [32], and molecular investigations have revealed their widespread occurrence in terrestrial ecosystems [33-38]. A large body of studies showed that microbial communities differ substantially across ecosystem types [36], with environmental or spatial factors as the major determinants structuring microbial communities [29-31]. However, the inconsistencies of targeted microbes, experimental methods, and heterogeneous ecological environment obstruct the comparison between these studies and the understanding of the relative influence of deterministic and stochastic processes. In fact, even within same microorganisms and ecosystems, there are still a number of factors to be considered when characterizing the underlying processes. For example, environmental factors may be spatially auto-correlated, and some ecological, climatic, or temporal variables may be left unmeasured, which collectively complicates the characterization of the relative importance of stochastic and deterministic processes.

Grasslands are an important part of the earth's many ecological communities, originally covering as much as $25 \%$ of the earth's surface, which is also a dominant landscape in China, and occupy $40 \%$ of the national land area [39]. They play important roles in preventing erosion and conserving biodiversity and potentially serve as a carbon sink to mitigate greenhouse gas emissions. China is characterized by four major grassland ecosystem types covering a distance of approximately $4500 \mathrm{~km}$ from northeast to southwest and spanning a latitude of $23^{\circ}$ [40]. The diverse ecosystem types and the broad spatial scale make grassland a suitable ecosystem to investigate the soil microbial biogeography. In this study, we collected 99 soil samples from various grassland ecosystems along a longitudinal gradient across seven provinces from east to west of China. These regions differ considerably in spatial structure, climatic conditions, and soil habitat, thus providing ideal sites to examine the relative importance of dispersal limitation and environmental filtering. We tested the relative
Fig. 1 Schematic diagram of dispersal limitation (a) and environmental filtering (b) processes. Dispersal limitation indicates the decaying of the similarity of species with increasing geographic distance. Environmental filtering suggests that the species similarity is negatively correlated with the increase of environmental heterogeneity

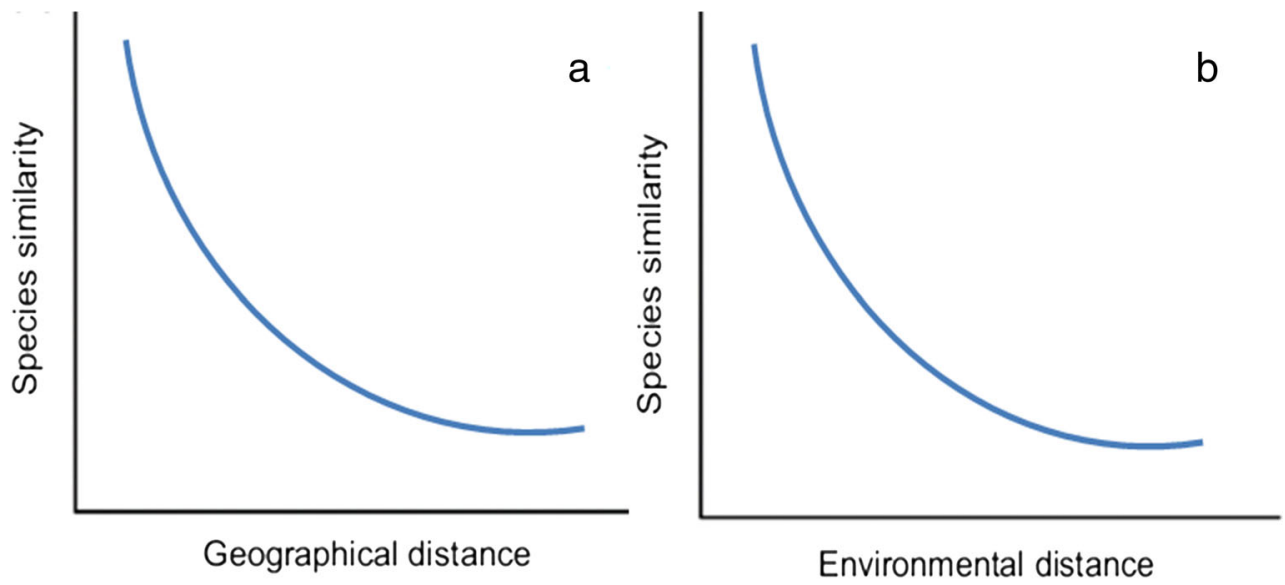


importance of stochastic and deterministic processes by comparing the variation in species dissimilarity with both geographic distance and environmental divergence. The objectives of this study were to (1) understand the biogeographical distribution patterns of soil microbial communities in grassland ecosystems and (2) to explore the underlying ecological processes that shape the distribution patterns.

\section{Methods}

\section{Sampling sites and soil collection}

This broad-scale investigation spans a long distance of $3283 \mathrm{~km}$ across various grassland ecosystems $\left(36^{\circ} 05^{\prime} \mathrm{N} \sim 49^{\circ}\right.$ $44^{\prime} \mathrm{N}$ and $84^{\circ} 01^{\prime} \mathrm{E} \sim 125^{\circ} 00^{\prime} \mathrm{E}$ ) in northern China. Detailed information about these sampling sites is shown in Tables S1 and S2 and Fig. S1. The sampling sites varied considerably in their climatic conditions with the average annual precipitation ranging between 42 and $467 \mathrm{~mm}$ and the average annual temperature between -3 and $12{ }^{\circ} \mathrm{C}$. The sampling regions span across seven provinces from the east to the west of China.

Soil sampling and vegetation surveys were conducted from August to December in 2012. In total, 99 sites were selected (Fig. S1) and three independent quadrats $(1 \times 1 \mathrm{~m})$ were established for plant community inventory at each site. Within each quadrat, taxonomy and the count of the grass species were recorded. Fifteen soil cores were randomly taken at a depth of $0-10 \mathrm{~cm}$ at each site using quincunx sampling method and homogenized into one sample. Visible stones, roots, and other residuals were removed in the field. Fresh soil samples were kept at $4{ }^{\circ} \mathrm{C}$ before being transported to the laboratory. Soil samples were passed through a $2.0-\mathrm{mm}$ sieve and stored at $4{ }^{\circ} \mathrm{C}$ until soil physical and chemical characterizations took place. Soil subsamples were quickly frozen using liquid nitrogen, lyophilized to constant weight, and stored at $-80{ }^{\circ} \mathrm{C}$ prior to DNA extraction.

\section{Soil physical and chemical characterizations}

Soil $\mathrm{pH}$ was measured using a soil to water ratio of 1:2.5 on a Delta pH meter (Mettler-Toledo Instruments Co., Columbus, $\mathrm{OH}, \mathrm{USA}$ ). Soil organic carbon (SOC) was determined using the $\mathrm{K}_{2} \mathrm{Cr}_{2} \mathrm{O}_{7}$ oxidation method. Total $\mathrm{N}$ (TN) was determined using the Dumas method with an Element Analyzer (Vario EL III, Elementar, Hanau, Germany) [41]. Soil nitrate $\left(\mathrm{NO}_{3}{ }^{-}-\mathrm{N}\right)$ and ammonium $\left(\mathrm{NH}_{4}{ }^{+}-\mathrm{N}\right)$ were determined with a Continuous Flow Analyzer (SAN ${ }^{++}$, Skalar, Breda, Holand) as previously described [42]. Soil available phosphorus was extracted with $0.5 \mathrm{M} \mathrm{NaHCO}_{3}$ and measured using the $\mathrm{Mo}-\mathrm{Sb}$ anti-spectrophotometry method [43]. Soil available potassium was extracted with $1 \mathrm{M}$ ammonium-acetate from air-dried samples and determined as previously described [44]. Soil moisture content was measured by oven-drying soil samples at $105{ }^{\circ} \mathrm{C}$ for $24 \mathrm{~h}$. Soil particle size (clay $<0.002 \mathrm{~mm}$, silt $0.002-0.05 \mathrm{~mm}$, and sand $>0.05 \mathrm{~mm}$ ) was determined using a Mastersizer 2000 Laser Diffraction Particle Analyzer (Malvern Instruments Ltd, Malvern, UK).

\section{DNA extraction and PCR amplification of bacterial and archaeal 16S rRNA genes}

Soil DNA was extracted using the Power Soil DNA Isolation Kits (MO BIO Laboratories, Carlsbad, CA, USA) according to the manufacturer's protocol, with a modification that the initial cell lysis procedure was performed on a FastPrep-24 DNA Isolation System (MP Biomedicals, Santa Ana, CA, USA) at a speed of $5.0 \mathrm{~m} \mathrm{~s}^{-1}$ for $40 \mathrm{~s}$. The concentration of extracted DNA was assessed using an IMPLEN P-330 NanoPhotometer UV/Vis spectrophotometer (IMPLEN, Munich, Germany).

The primers $515 \mathrm{f}$ and $806 \mathrm{r}$ [45] were employed to amplify the bacterial and archaeal 16S rRNA genes from the extracted DNA, with a 12-bp bar code linked to the $5^{\prime}$ end of the reverse primer as previously described [46]. The $50-\mu \mathrm{l}$ PCR reaction mixtures contained $4 \mu \mathrm{l}$ of DNA template, $1 \mu \mathrm{l}$ of each primer $(10 \mu \mathrm{M})$, $25 \mu$ Premix Taq ${ }^{\text {TM }}$ (Takara Biotechnology, Dalian, China), and $19 \mu \mathrm{l}$ of sterilized $\mathrm{ddH}_{2} \mathrm{O}$. The thermal cycling conditions were as follows: $3 \mathrm{~min}$ at $94{ }^{\circ} \mathrm{C}$, followed by 35 cycles of $45 \mathrm{~s}$ at $94{ }^{\circ} \mathrm{C}, 60 \mathrm{~s}$ at $50^{\circ} \mathrm{C}$ and $90 \mathrm{~s}$ at $72^{\circ} \mathrm{C}$, and $10 \mathrm{~min}$ at $72^{\circ} \mathrm{C}$. The PCR products were purified using a Wizard SV Gel and PCR Clean-Up System (Promega, San Luis Obispo, CA, USA) and sent for $2 \times 150$-bp paired-end sequencing on an Illumina MiSeq sequencer (Illumina, Inc., San Diego, CA, USA).

\section{Sequence processing}

Following the $2 \times 150$-bp paired-end sequencing, raw Illumina FASTQ files were de-multiplexed, quality filtered, and analyzed using Quantitative Insights into Microbial Ecology (QIIME) v1.8.0 [47]. Briefly, raw reads were merged together using the Fast Length Adjustment of Short reads (FLASH), and $95 \%$ of the bases sequenced had quality scores higher than 30 [48]. Reads were truncated at any site containing more than three consecutive bases, and any reads containing ambiguous base calls and shorter than $190 \mathrm{nt}$ were discarded. A chimera filtering approach UPARSE [49] was employed to bin the sequences into operational taxonomic units (OTUs) at a $97 \%$ sequence identity. Representative sequences were extracted from each OTU, sequence alignment was performed with PyNAST [50], and taxonomy assignment by the Ribosomal Database Project (RDP) [51] based on the latest released Greengenes database [52]. Resampling process was implemented at a depth of 50,967 sequences per sample for diversity analysis. 


\section{Data analysis}

The Global Position System (GPS) coordinates for each site were converted to Universal Transverse Mercator coordinates in meters prior to the Mantel test and partial Mantel test using the vegan library in R software. Environmental variables listed in Table S3 were standardized (mean $=0$ and standard deviation=1) for Spearman's rank correlation (SPSS 19.0, IBM Co., Armonk, NY, USA). Climatic factors including mean annual temperature, mean annual precipitation, and the remaining 12 factors (Tables S1 and S2) were obtained from the WorldClim [53]. Plant taxonomy was identified based on the Angiosperm Phylogeny Group (APG) III system [54]. OTUs at the $97 \%$ similarity for bacteria and archaea were used in the downstream analyses.

The microbial communities with a relative abundance higher than $0.5 \%$ at the phylum level were displayed in the heat map using the pheatmap package (R software 2014). The richness pattern was analyzed in ArcGIS 9.3 using the ordinary kriging interpolation (ESRI, Redlands, CA, USA). The Euclidean distances of spatial and environmental variables between each pair of sites were calculated before the Mantel test based on 10,000 randomizations of the original data, and the importance of each variable was evaluated with the Spearman's correlation coefficient.

A structural equation model (SEM) was constructed using AMOS 21.0 (SPSS Inc., IBM Co., Armonk, NY, USA) to analyze the direct and indirect impacts of spatial and environmental factors on the beta diversity pattern. Firstly, the factors were converted into distance matrices; for example, unweighted UniFrac distance and Bray-Curtis distance were calculated for the beta diversity of soil prokaryote community and plant community, respectively. Euclidean distance was calculated for richness, climatic factors (14 factors in Table S2), soil texture (percent of silt and percent of sand), and soil nutrients (SOC, $\mathrm{TN}, \mathrm{NO}_{3}{ }^{-}-\mathrm{N}, \mathrm{NH}_{4}{ }^{+}-\mathrm{N}$, soil available phosphorus, and soil available potassium). Mantel test was employed to calculate the correlations between those matrices, and the resultant covariance matrix was used as the input data for AMOS. Model fits were determined according to a non-significant $\chi^{2}$ test $(P>0.05)$, low Akaike value (AIC), high goodnessof-fit index (GFI; $>0.90)$, and low root square mean error of approximation $(\mathrm{RMSEA} ;<0.05)$ [55].

\section{Results}

\section{The composition of plant and soil microbial communities}

In total, 105 species were identified for the plant communities, and 24 species of them had species frequency higher than $5 \%$ in individual quadrats, including Cleistogenes songorica, Bothriochloa ischaemum, and Leymus chinensis. Meadow steppe in the eastern part of the study area was dominated by herbaceous perennial mesophytic and xerophytic species, such as C. songorica, Achnatherum extremiorientale, and L. chinensis. Typical steppe is distributed across the middle part of the region, dominated by typical xerophytic species, such as B. ischaemum, Stipa krylovii Roshev, Suaeda glauca, and L. chinensis. Desert steppe is distributed in the western region, where dry-tolerant, short grasses such as $S$. krylovii Roshev and Stipa gobica Roshev were prevailing. Alpine steppe occupies a small area and is distributed in the western part, primarily dominated by Carex scabrirostris Kükenth, Kobresia pygmaea, and Potentilla bifurca.

A high number of 13,392,210 high-quality bacterial/archaeal $16 \mathrm{~S}$ rRNA gene reads were obtained through the highthroughput sequencing and could be classified into 37,660 OTUs at a $97 \%$ sequence similarity. The top 23 phyla with the relative abundance of the total microbial community higher than $0.5 \%$ are shown in a heat map (Fig. 2). The microbial communities were dominated by Proteobacteria, Actinobacteria, Acidobacteria, Chloroflexi, and Planctomycetes across the 99 soil samples, with their relative abundances ranging from 10.0-42.0, 4.01-41.0, 0.00-33.0, 2.03-29.0, and 2.01-13.0\%, respectively, in individual samples. In addition, the remaining three abundant phyla (Gemmatimonadetes, Bacteroidetes, and Verrucomicrobia) were comprising up to $15 \%$ of the total microbial community in individual soil samples (Fig. 2).

\section{Relationships between the dominant microbial taxa and environmental factors}

Spearman's correlation analysis found that Proteobacteria were significantly and positively related to the precipitation of the driest month $(r=0.50, n=99, P<0.01)$, and the remaining significant impact factors were mainly classified into climatic factors (Tables S1 and S2). Actinobacteria had significantly negative relationships with climatic factors, and the most significant one was the precipitation of the driest month $(r=-0.33$, $n=99, P<0.01)$. Furthermore, soil $\mathrm{pH}$, generally recognized as an integrative and key environmental factor, had significant correlations with Acidobacteria, Gemmatimonadetes, Bacteroidetes, and Verrucomicrobia. We also found that SOC and TN were remarkable environmental factors (Table S3).

\section{The patterns of microbial richness}

Geographical distance had negligible impacts on the microbial OTU richness $(r=0.08, n=99, P>0.05)$, and regional scale differences in OTU richness could also be observed (Fig. 3). Soil microbial OTU richness ranging from 43 to 284 was conspicuously lower in the west of the region than the other parts of the region where OTU richness was ranging from 42 to 354. By contrast, higher richness of soil microbial communities was observed in the middle region with higher annual precipitation 
Fig. 2 Heat map showing the relative abundance and distribution of the top 23 abundant phyla of the total microbial community in the grassland ecosystems. These top 23 phyla represented $99.4 \%$ of the sequences. Dendrogram at left indicates the relatedness of soil microbial community structures for the 99 samples. The gray column below the heat map indicates the detail sampling sites along longitude. The color-coded column at the right of the heat map corresponds to the relative abundance of each phylum

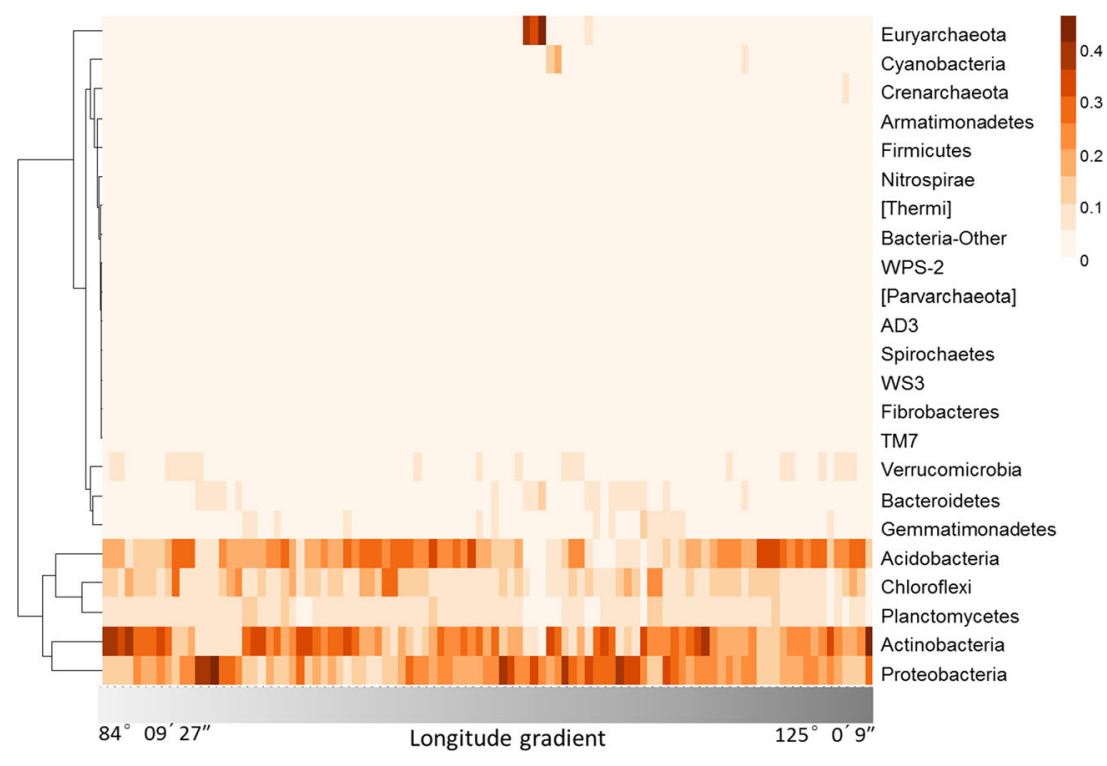

( $r=0.58, n=99, P<0.01$; Tables $\mathrm{S} 1$ and S2). These results could be due to the relatively higher annual precipitation in most parts of the middle regions (369-467 mm) as compared with the average level of $257 \mathrm{~mm}$ in other sites.

\section{Relationships between beta diversity and environmental distance or geographic distance}

Mantel test was performed to explore the relative importance of dispersal limitation and environmental filtering processes in shaping the microbial beta diversity. The dispersal limitation process hypothesizes that geographic distance would impact the community structure (Fig. 1a), while the environmental filtering suggests that the species assembling is governed by the divergence of environmental conditions (Fig. 1b). Mantel test showed that geographic distance was positively correlated with the UniFrac dissimilarity matrices $(r=0.11, n=99$, $P<0.05$; Fig. 4a), indicating a significant distance decay relationship. However, after controlling for environmental distance, spatial distance was not significantly correlated with UniFrac dissimilarity matrices (partial Mantel test; Table 1). Environmental divergence also had a significant positive relationship with the beta diversity index $(r=0.36, n=99$, $P<0.01)$. The increase of environmental divergence obviously enhanced the beta diversity of soil microbial communities and thus suggested an environmental filtering process (Fig. 4b). After controlling for spatial distance, environmental distance was still significantly correlated with UniFrac dissimilarity matrices $(r=0.34, n=99, P<0.01$; Table 1$)$.

\section{The main factors impacting the beta diversity patterns}

A SEM was constructed to evaluate the direct and indirect effects of spatial factors, climatic factors, soil $\mathrm{pH}$, soil texture, and nutrients on the patterns of soil microbes and plants. The final SEM adequately fitted the data input derived from the Mantel test $\left(\chi^{2}=0.764\right.$, degrees of freedom $=6, P=0.998$, RMSEA $<0.001, \mathrm{GFI}=0.998, \mathrm{AIC}=42.8)$. Overall, this model could explain 74 and $91 \%$ of the variance in community (beta diversity) for soil microorganisms and plants, respectively (Fig. 5).

The dominant factors influencing the beta diversity patterns of plants and soil microorganisms were quite similar (Fig. 5). In particular, climatic factors significantly influenced the beta diversity of soil prokaryotes $(\lambda=0.34, P<0.001)$ and the beta diversity of plants $(\lambda=0.26, P<0.05)$. Soil $\mathrm{pH}$ showed a strong effect on the prokaryotic beta diversity $(\lambda=0.21$, $P<0.05)$ but not on the plant beta diversity. The remaining factors had no significant direct effect on the beta diversity of plant and soil microbial communities, using the SEM. Negligible positive impacts were obtained between the beta diversity of plant and soil microbial communities, which was different from the results of Mantel test. The beta diversity of plant conspicuously impacted the beta diversity of soil microbial communities ( $r=0.28, n=99, P<0.01$; Fig S2). In summary, environmental factors, especially the climatic factors, were the determinative drivers structuring the beta diversity of soil microbial communities, based on the direct and total effects (Table 2).

\section{Discussion}

Previous investigations suggested that grassland ecosystems encompass relatively more diverse microbial communities than other ecosystem types (e.g., desert ecosystem and arctic tundra) $[36,56]$. Within grassland habitats, most studies revealed that the dominant taxa of soil microbial communities 


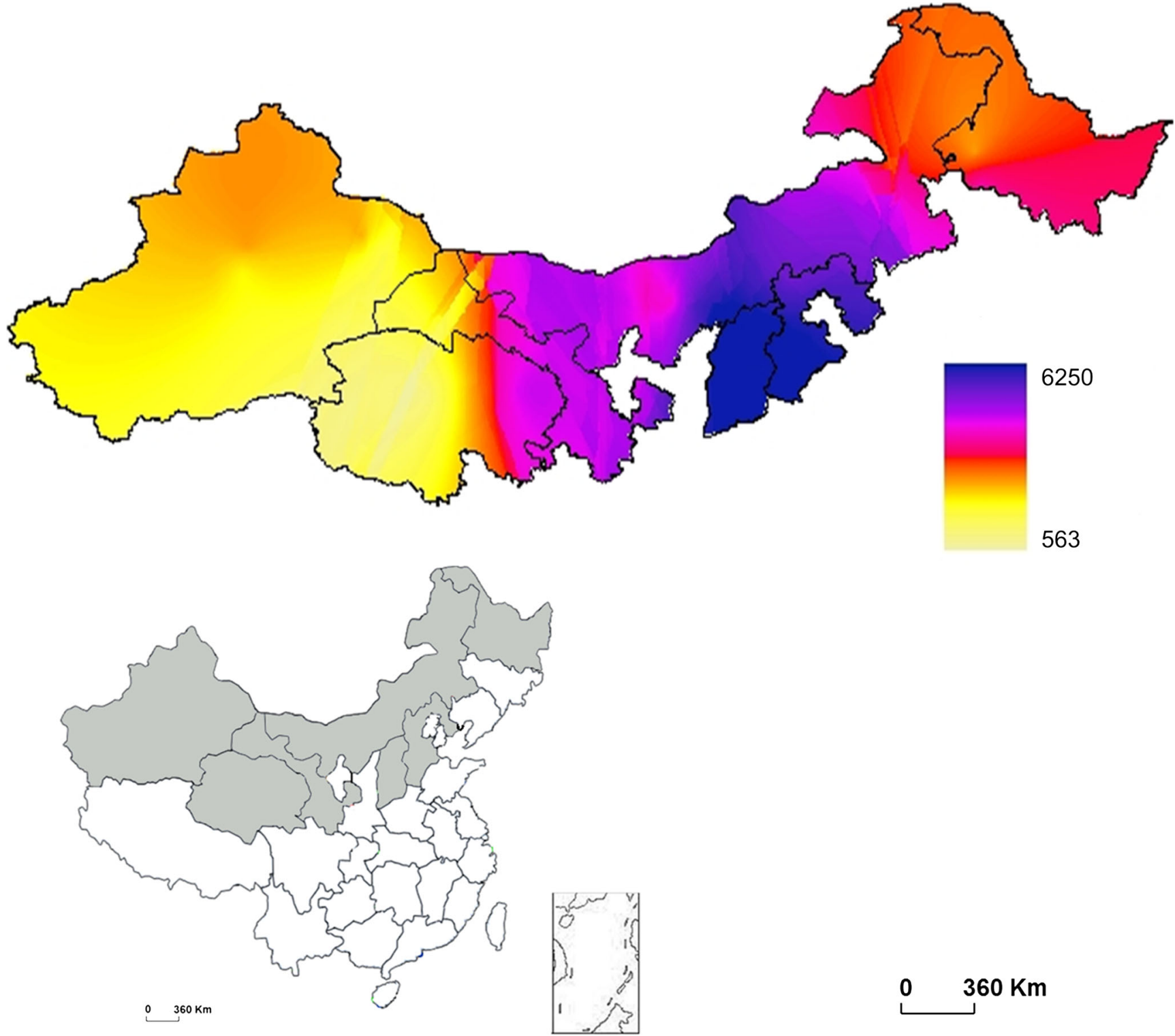

Fig. 3 Maps showing the interpolated OTU richness of soil microorganisms analyzed with the kriging algorithm. Different colors indicated different OTU richness of the soil microorganisms. From the

were quite similar, which is also corroborated by our study (Fig. 2). For example, Proteobacteria, Actinobacteria, Acidobacteria, Chloroflexi, and Planctomycetes found to be dominant in our study are bacterial phyla known to be highly abundant and ubiquitous in other grassland soils $[17,36,56$, 57]. The phylum Proteobacteria ranged from 10.0 to $42.0 \%$ in this study, and they currently contain 528 named and described genera [58]. Members of the phylum Actinobacteria made up an average of $21.4 \%$ of soil bacterial communities. The phylum Actinobacteria commonly contains three subclasses in soil, and many of them are well known and fully studied [58]. The Acidobacteria phylum were ranging from 0.00 to $33.0 \%$, in general, which were more sensitive with soil $\mathrm{pH}[59,60]$. In this case, the pattern was most likely upper color scale to the lower, the change from OTU-rich sites to sites with fewer OTUs was indicated

driven by the previously observed phenomenon that soil $\mathrm{pH}$ largely governs the distributions of many soil acidobacterial taxa [59]. Members of the phylum Chloroflexi made up an average of $11.3 \%$ of soil bacterial communities, and this phylum is affiliated with a number of the candidate classes and so may display quite different physiologies [61], such as the only one isolate from soil was a filamentous aerobic heterotroph, but no conclusions could be drawn yet about the general properties of soil chloroflexi [62]. The planctomycetes are a group of budding bacteria [63], and most isolates of this phylum were from aquatic environments, and it was not clear whether these are physiologically and genetically good models for soil planctomycetes [62]. 

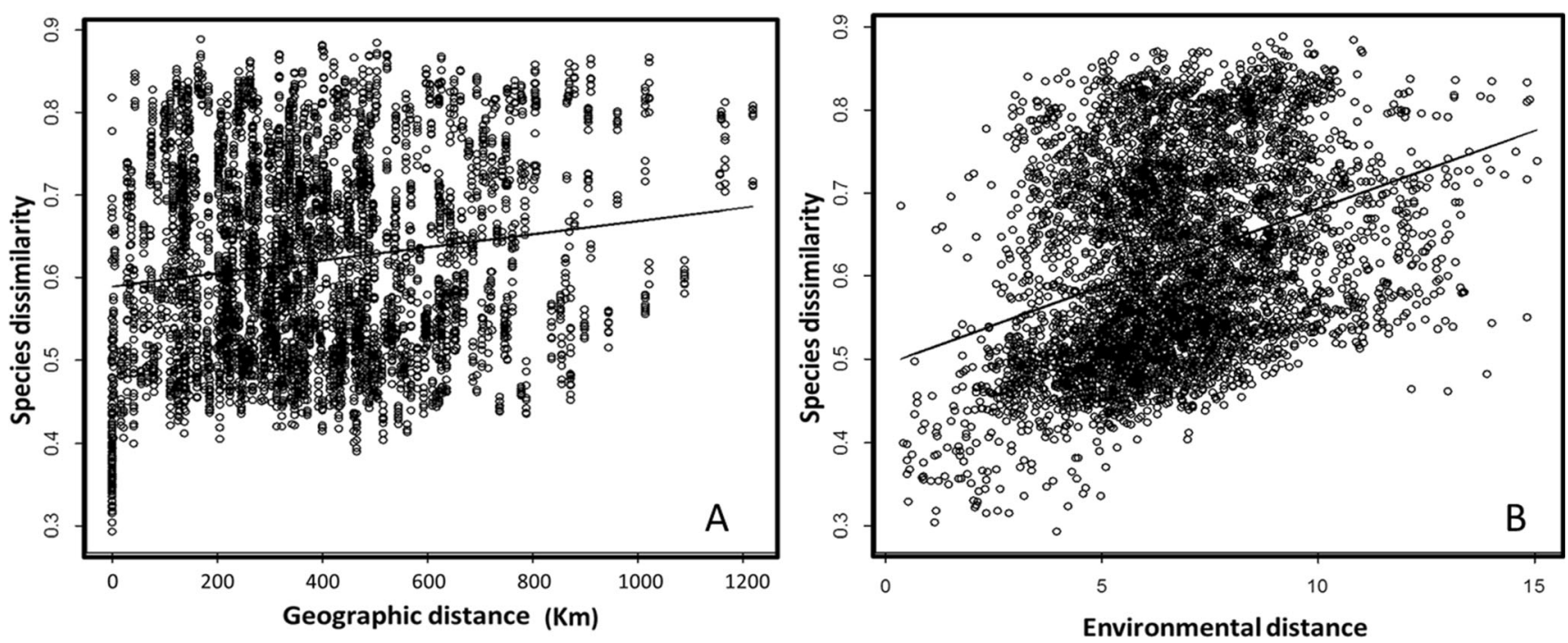

Fig. 4 Correlations between the beta diversity of soil microbial community and geographic distance (a) or environmental distance (b). The environmental distance between each pair of sites was estimated as the Euclidean distance in multi-dimensional environmental space

Soils are highly heterogeneous environments containing enormously diverse prokaryotic communities [64, 65]. Previous studies have covered various aspects of soil microbial diversity, including levels of species richness [34, 66], and abiotic/biotic factors impacting diversity and composition of communities $[60,67]$. In this study, prokaryotic richness was strongly related to annual precipitation, which was in consistence with the water-energy dynamics [68], which was used to test the species richness patterns with climates. Hence, at the level of richness and beta-diversity, soil microbial community patterns matched those of macroorganisms, which was similarly and significantly influenced by climatic factors [68, 69].

The relative importance of stochastic and deterministic processes in structuring the beta diversity patterns was substantially debated in previous studies [10, 24, 30, 31, 70]. Knowledge of the biodiversity patterns of microbial communities in grassland soils is important to predict the responses of grassland ecosystems to future environmental and anthropogenic changes $[17,29,36,60]$. In this study, we tested the

Table 1 Mantel and partial Mantel tests for the correlation between $\beta$ dissimilarity index and the geographic distance or environmental distance using Spearman's rho

\begin{tabular}{lll}
\hline Effects of & Controlling for & $\begin{array}{l}R \text { value of the } \\
\text { correlation }\end{array}$ \\
\hline Geographic distance & & $0.11^{*}$ \\
Environmental distance & Environmental distance & 0.02 \\
Geographic distance & Geographic distance & $0.34^{* *}$ \\
Environmental distance & G \\
\hline
\end{tabular}

The significances are tested based on 10,000 permutations

$* P<0.05$

$* * P<0.01$ competing effect of stochastic and deterministic processes concerning the changes in dissimilarity of species composition with geographic distance and environmental heterogeneity, by focusing on regional scale in which the environment was spatially structured. We identified a significant trend of increasing dissimilarities in the bacterial communities with increasing environmental heterogeneity. The results showed that the environmental divergence-dissimilarity relationship was strong in grassland ecosystems, which indicated that environmental filtering process might be more important than dispersal limitation process. Partial mantel test analysis also revealed the same trend that the contribution of independent environmental variables had a significant positive relationship

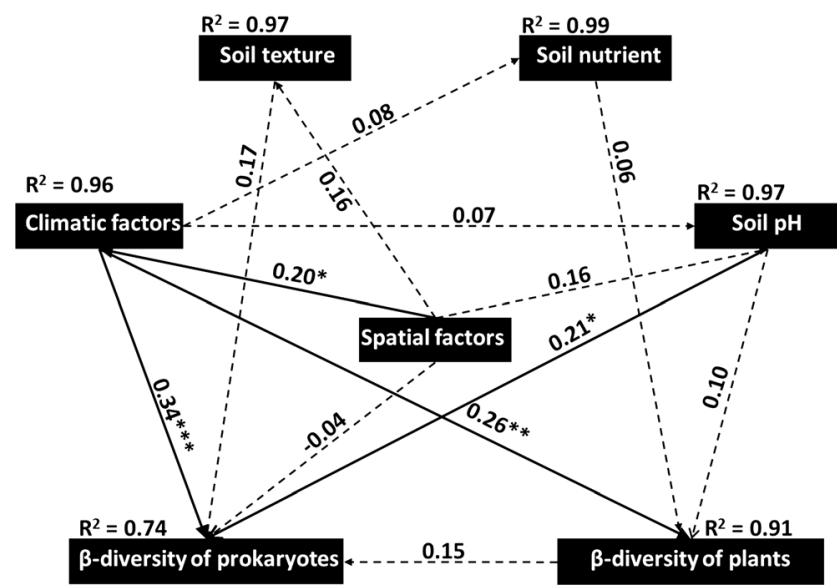

Fig. 5 Path diagrams from structural equation model (SEM) describing the direct and indirect effects of the different variable groups in explaining the variations of $\beta$-diversity of prokaryotes. Numbers associated with single headed arrows are partial regression coefficients of multiple regressions $(* * * P<0.001, * * P<0.01$, and $* P<0.05)$, and solid line indicated significantly relationship, while the dashed line was non-significant. The unexplained variation $\left(1-R^{2}\right)$ represented the effect of unmeasured variables and measurement error 
Table 2 The direct and indirect contributions of different variable groups in explaining the variations of $\beta$-diversity of prokaryotes derived from the structural equation model analysis

\begin{tabular}{llll}
\hline Variable groups & Direct path & Indirect path & Total effect \\
\hline Soil texture & 0.17 & 0.01 & 0.18 \\
Soil nutrient & 0.00 & 0.01 & 0.01 \\
Soil pH & 0.21 & 0.01 & 0.22 \\
Climatic factors & 0.34 & 0.06 & 0.40 \\
Spatial factors & -0.04 & 0.15 & 0.11 \\
$\beta$-diversity of plants & 0.15 & 0.00 & 0.15 \\
\hline
\end{tabular}

with beta diversity, while the spatial distance did not obviously impact the beta diversity when controlling for environmental variables. Therefore, deterministic process played a more important role than stochastic process in the pattern of beta diversity of soil microbial communities, supporting the predictions of niche theory which indicated that species were able to reach all sites where environments were suitable and this habitat specialization process was a classic deterministic process driven by environmental heterogeneity deterministic; thus, species beta diversity pattern was simply determined by the divergence degree of environmental conditions between sites $[28,71,72]$. These findings are in consistence with results from previous studies. For example, Casamayor and Barberán [73] concluded that the environment (especially the composition and concentration of salinity), rather than geographic distance per se, structured beta diversity of bacterioplankton in oceans and lakes at global scale. Zinger et al. [74] found that pattern of bacterial beta diversity in global-scale oceans was significantly influenced by the productivity of seawater. Wang et al. [31] stated that environmental variables imposed strong selection pressures on the beta diversity of bacterial communities for nearly all samples, thus indicating a dominant effect of deterministic processes on bacterial assemblages.

SEM analysis revealed that climate had a strong direct effect on plant and prokaryotic beta diversity and indirectly affected these metrics by altering edaphic conditions (Table 1 and Fig. 5). These results were also corroborated by the relationships between dominant taxa and the environmental factors (Table S3). The change of soil $\mathrm{pH}$ was positively correlated with the variance of prokaryotic beta diversity in pairs of sites (Fig. 5) but had no significantly direct effect on plant beta diversity according to SEM. Soil $\mathrm{pH}$, as the most important factor in soil habitat as revealed by our previous results [42], could impose strong selective pressures. At local scale (i.e., centimeters to meters), soil biota composition is often explained by variation in the physical and chemical properties of soil, such as soil water, carbon, and nutrition, as well as the influence of dominant plants determining substrates entering the soil $[28,75]$. While, at regional or continental scales (i.e., meters to thousands of kilometers), other factors such as climate, topography, may have a more important role $[28,67]$. In this study, SEM well explained the impact of environmental and spatial factors on soil microbial beta diversity, but there still was a part of residual variation (26\%) remaining unexplained, which had differential impacts on plant beta diversity. Although the underlying influence could not be fully identified from the existing data, analyses implied that they could be caused by some unmeasured variables or by spatial structures that have been missed and required more complex functions to be described [76]. Thus, as many environmental factors as possible should be included and classified to give a comprehensive view of the influence of ecological process and to distinguish the original variables from the derived variables.

\section{Conclusion}

In this study, ecological theories for macroorganisms were applied to explore the beta diversity of the microorganism communities. We examined the relative importance of stochastic and deterministic processes in structuring the beta diversity of microbial communities in grassland ecosystems. We provide evidence that the environmental divergence-dissimilarity relationship was obviously strong and environmental filtering process was obviously clear. Therefore, the deterministic process played a more important role than the stochastic process in the pattern of beta diversity of soil microbial communities which is in consistence with the findings from macroecological studies.

Acknowledgments This work was supported by the Ministry of Science and Technology 2013CB956300 and Chinese Academy of Sciences (XDB15020200, STSN-21-02) and the Natural Science Foundation of China (41230857). We are very grateful to Peng Han, Liang Xiang, Dr. Jing Li, Prof. Baodong Chen, and Prof. Weiping Chen for their assistance in soil sampling and analyzing.

\section{References}

1. Gaston KJ (2000) Global patterns in biodiversity. Nature 405(6783):220-227

2. Rohwer F, Seguritan V, Azam F, Knowlton N (2002) Diversity and distribution of coral-associated bacteria. Mar Ecol Prog Ser 243:110

3. Green JL, Holmes AJ, Westoby M, Oliver I, Briscoe D, Dangerfield $M$ et al (2004) Spatial scaling of microbial eukaryote diversity. Nature 432(7018):747-750

4. Reche I, Pulido-Villena E, Morales-Baquero R, Casamayor EO (2005) Does ecosystem size determine aquatic bacterial richness? Ecology 86(7):1715-1722

5. MacArthur RH (1965) Patterns of species diversity. Biol Rev 40(4): $510-533$ 
6. Tang Z, Fang J, Chi X, Yang Y, Ma W, Mohhamot A, Guo Z, Liu Y, Gaston KJ (2012) Geography, environment, and spatial turnover of species in China's grasslands. Ecography 35(12):1103-1109

7. Rodríguez P, Arita HT (2004) Beta diversity and latitude in North American mammals: testing the hypothesis of covariation. Ecography 27(5):547-556

8. Qian H, Ricklefs RE (2007) A latitudinal gradient in large-scale beta diversity for vascular plants in North America. Ecol Lett 10(8):737-744

9. Soininen J, Lennon JJ, Hillebrand H (2007) A multivariate analysis of beta diversity across organisms and environments. Ecology 88(11):2830-2838

10. Kraft NJ, Comita LS, Chase JM, Sanders NJ, Swenson NG, Crist TO, Stegen JC, Vellend M, Boyle B, Anderson MJ (2011) Disentangling the drivers of $\beta$ diversity along latitudinal and elevational gradients. Science 333(6050):1755-1758

11. Buckley LB, Jetz W (2008) Linking global turnover of species and environments. Proc Natl Acad Sci U S A 105(46):17836-17841

12. Harrison S, Ross SJ, Lawton JH (1992) Beta diversity on geographic gradients in Britain. J Appl Ecol 61(1):151-158

13. Qian H, Ricklefs RE, White PS (2005) Beta diversity of angiosperms in temperate floras of eastern Asia and eastern North America. Ecol Lett 8(1):15-22

14. Graham CH, Moritz C, Williams SE (2006) Habitat history improves prediction of biodiversity in rainforest fauna. Proc Natl Acad Sci U S A 103(3):632-636

15. McKnight MW, White PS, McDonald RI, Lamoreux JF, Sechrest W, Ridgely RS et al (2007) Putting beta-diversity on the map: broad-scale congruence and coincidence in the extremes. PLoS Biol 5(10):e272

16. Yan Y, Yang X, Tang Z (2013) Patterns of species diversity and phylogenetic structure of vascular plants on the Qinghai-Tibetan Plateau. Ecol Evol 3(13):4584-4595

17. Prober SM, Leff JW, Bates ST, Borer ET, Firn J, Harpole WS, Lind EM, Seabloom EW, Adler PB, Bakker JD (2015) Plant diversity predicts beta but not alpha diversity of soil microbes across grasslands worldwide. Ecol Lett 18(1):85-95

18. Ranjard L, Dequiedt S, Chemidlin Prévost-Bouré N et al (2013) Turnover of soil bacterial diversity driven by wide-scale environmental heterogeneity. Nat Commun 4:1434

19. Chemidlin Prévost-Bouré N, Dequiedt S, Thioulouse J et al (2014) Similar processes but different environmental filters for soil bacterial and fungal community composition turnover on a broad spatial scale. PLoS One 9:e111667

20. Powell JR, Karunaratne S, Campbell CD et al (2015) Deterministic processes vary during community assembly for ecologically dissimilar taxa. Nat Commun 6:8444

21. MacArthur RH, Wilson EO (1967) The theory of island biogeography. Princeton University Press, Princeton

22. Bell G (2001) Neutral macroecology. Science 293(5539):2413

23. Hubbell SP (2001) The unified neutral theory of biodiversity and biogeography. Princeton University Press, Princeton

24. Caruso T, Chan Y, Lacap DC, Lau MC, McKay CP, Pointing SB (2011) Stochastic and deterministic processes interact in the assembly of desert microbial communities on a global scale. ISME J 5(9): 1406-1413

25. Lebrija-Trejos E, Pérez-García EA, Meave JA, Bongers F, Poorter L (2010) Functional traits and environmental filtering drive community assembly in a species-rich tropical system. Ecology 91(2): 386-398

26. Graham CH, Fine PV (2008) Phylogenetic beta diversity: linking ecological and evolutionary processes across space in time. Ecol Lett 11(12):1265-1277

27. Cavender-Bares J, Kozak KH, Fine PV, Kembel SW (2009) The merging of community ecology and phylogenetic biology. Ecol Lett 12(7):693-715
28. Martiny JBH, Bohannan BJM, Brown JH, Colwell RK, Fuhrman JA, Green JL, Horner-Devine MC, Kane M, Krumins JA, Kuske CR, Morin PJ, Naeem S, Ovreas L, Reysenbach AL, Smith VH, Staley JT (2006) Microbial biogeography: putting microorganisms on the map. Nat Rev Microbiol 4(2):102-112

29. Fierer N (2008) Microbial biogeography: patterns in microbial diversity across space and time. Accessing uncultivated microorganisms: from the environment to organisms and genomes and back. ASM Press, Washington DC, pp 95-115

30. Schiaffino MR, Unrein F, Gasol JM, Massana R, Balagué V, Izaguirre I (2011) Bacterial community structure in a latitudinal gradient of lakes: the roles of spatial versus environmental factors. Freshw Biol 56(10):1973-1991

31. Wang J, Shen J, Wu Y, Tu C, Soininen J, Stegen JC, He J, Liu X, Zhang L, Zhang E (2013) Phylogenetic beta diversity in bacterial assemblages across ecosystems: deterministic versus stochastic processes. ISME J 7(7):1310-1321

32. Hu HW, Chen DL, He JZ (2015) Microbial regulation of terrestrial nitrous oxide formation: understanding the biological pathways for prediction of emission rates. FEMS Microbiol Rev. doi:10.1093/ femsre/fuv021

33. Fisk MC, Ruether KF, Yavitt JB (2003) Microbial activity and functional composition among northern peatland ecosystems. Soil Biol Biochem 35(4):591-602

34. Fierer N, Breitbart M, Nulton J, Salamon P, Lozupone C, Jones R, Robeson M, Edwards RA, Felts B, Rayhawk S (2007) Metagenomic and small-subunit rRNA analyses reveal the genetic diversity of bacteria, archaea, fungi, and viruses in soil. Appl Environ Microb 73(21):7059-7066

35. Hansel CM, Fendorf S, Jardine PM, Francis CA (2008) Changes in bacterial and archaeal community structure and functional diversity along a geochemically variable soil profile. Appl Environ Microb 74(5):1620-1633

36. Fierer N, Leff JW, Adams BJ, Nielsen UN, Bates ST, Lauber CL, Owens S, Gilbert JA, Wall DH, Caporaso JG (2012) Cross-biome metagenomic analyses of soil microbial communities and their functional attributes. Proc Natl Acad Sci 109(52):21390-21395

37. Wang JT, Cao P, Hu HW, Li J, Han LL, Zhang LM et al (2015) Altitudinal distribution patterns of soil bacterial and archaeal communities along Mt. Shegyla on the Tibetan Plateau. Microb Ecol 69(1):135-145

38. Zelenev VV, van Bruggen AHC, Semenov AM (2005) Short-term wavelike dynamics of bacterial populations in response to nutrient input from fresh plant residues. Microb Ecol 49(1):83-93

39. Kang L, Han X, Zhang Z, Sun OJ (2007) Grassland ecosystems in China: review of current knowledge and research advancement. Philos T R Soc B 362(1482):997-1008

40. Sun H (2005) Ecosystems of China. Science Press, Beijing

41. McGill WB, Rutherford PM, Figueiredo CT \& Arocena JM (2007) Total nitrogen. Soil sampling and methods of analysis, 2nd edn (Carter MR \& Gregorich EG, eds), pp. 239-250. CRC press, Taylor and Francis Group, London, UK

42. Cao P, Zhang L-M, Shen J-P, Zheng Y-M, Di HJ, He J-Z (2012) Distribution and diversity of archaeal communities in selected Chinese soils. FEMS Microbiol Ecol 80(1):146-158

43. Frank K, Beegle D, Denning J (1998) Phosphorus. In: Brown JR (ed) Recommended chemical soil test procedures for the North Central Region. NCR Publication No. 221. Missouri Agricultural Experiment Station, Columbia, pp 24-32

44. Warncke D, Brown JR (1998) Potassium and other basic cations. In: Brown JR (ed) Recommended chemical soil test procedures for the North Central Region. NCR Publication No. 221. Missouri Agricultural Experiment Station, Columbia, pp 33-39

45. Caporaso JG, Lauber CL, Walters WA, Berg-Lyons D, Lozupone CA, Turnbaugh PJ, Fierer N, Knight R (2011) Global patterns of 
16S rRNA diversity at a depth of millions of sequences per sample. Proc Natl Acad Sci U S A 108(Supplement 1):4516-4522

46. Caporaso JG, Lauber CL, Walters WA, Berg-Lyons D, Huntley J, Fierer N, Owens SM, Betley J, Fraser L, Bauer M (2012) Ultrahigh-throughput microbial community analysis on the Illumina HiSeq and MiSeq platforms. ISME J 6(8):1621-1624

47. Caporaso JG, Kuczynski J, Stombaugh J, Bittinger K, Bushman FD, Costello EK, Fierer N, Pena AG, Goodrich JK, Gordon JI (2010) QIIME allows analysis of high-throughput community sequencing data. Nat Methods 7(5):335-336

48. Magoč T, Salzberg SL (2011) FLASH: fast length adjustment of short reads to improve genome assemblies. Bioinformatics 27(21): 2957-2963

49. Edgar RC (2013) UPARSE: highly accurate OTU sequences from microbial amplicon reads. Nat Methods 10(10):996-998

50. Caporaso JG, Bittinger K, Bushman FD, DeSantis TZ, Andersen GL, Knight R (2010) PyNAST: a flexible tool for aligning sequences to a template alignment. Bioinformatics 26(2):266-267

51. Wang Q, Garrity GM, Tiedje JM, Cole JR (2007) Naive Bayesian classifier for rapid assignment of rRNA sequences into the new bacterial taxonomy. Appl Environ Microb 73(16):5261-5267

52. McDonald D, Price MN, Goodrich J, Nawrocki EP, DeSantis TZ, Probst A, Andersen GL, Knight R, Hugenholtz P (2012) An improved Greengenes taxonomy with explicit ranks for ecological and evolutionary analyses of bacteria and archaea. ISME J 6(3):610 618

53. Hijmans RJ, Cameron SE, Parra JL, Jones PG, Jarvis A (2005) Very high resolution interpolated climate surfaces for global land areas. Int J Climatol 25(15):1965-1978

54. Chase MW, Reveal JL (2009) A phylogenetic classification of the land plants to accompany APG III. Bot J Linn Soc 161(2):122-127

55. Grace JB, Keeley JE (2006) A structural equation model analysis of postfire plant diversity in California shrublands. Ecol Appl 16(2): 503-514

56. Portillo MC, Leff JW, Lauber CL, Fierer N (2013) Cell size distributions of soil bacterial and archaeal taxa. Appl Environ Microb 79(24):7610-7617

57. Zhou X, Chen C, Wang Y (2012) Long-term exclusion of grazing increases soil microbial biomass but not diversity in a temperate grassland. Open J Soil Sci 2(4):364-371

58. Garrity GM, Bell JA, Lilburn TG (2004) Taxonomic outline of the prokaryotes, release 5.0. Springer-Verlag, New York

59. Jones RT, Robeson MS, Lauber CL, Hamady M, Knight R, Fierer N (2009) A comprehensive survey of soil acidobacterial diversity using pyrosequencing and clone library analyses. ISME J 3(4): $442-453$

60. Lauber CL, Hamady M, Knight R, Fierer N (2009) Pyrosequencing-based assessment of soil $\mathrm{pH}$ as a predictor of soil bacterial community structure at the continental scale. Appl Environ Microb 75(15):5111-5120

61. Rappe' MS, Giovannoni SJ (2003) The uncultured microbial majority. Annu Rev Microbiol 57:369-394

62. Janssen PH (2006) Identifying the dominant soil bacterial taxa in libraries of 16S rRNA and 16S rRNA genes. Appl Environ Microb 72(3):1719-1728

63. Fuerst JA (2005) Intracellular compartmentation in planctomycetes. Annu Rev Microbiol 59:299-328

64. Torsvik V, Goksøyr J, Daae FL (1990) High diversity in DNA of soil bacteria. Appl Environ Microb 56(3):782-787

65. Curtis TP, Sloan WT, Scannell JW (2002) Estimating prokaryotic diversity and its limits. Proc Natl Acad Sci U S A 99(16):10494 10499

66. Roesch LF, Fulthorpe RR, Riva A, Casella G, Hadwin AK, Kent AD, Daroub SH, Camargo FA, Farmerie WG, Triplett EW (2007) Pyrosequencing enumerates and contrasts soil microbial diversity. ISME J 1(4):283-290

67. Fierer N, Jackson RB (2006) The diversity and biogeography of soil bacterial communities. Proc Natl Acad Sci U S A 103(3):626-631

68. O'Brien EM, Field R, Whittaker RJ (2000) Climatic gradients in woody plant (tree and shrub) diversity: water-energy dynamics, residual variation, and topography. Oikos 89(3):588-600

69. Field R, O'Brien EM, Whittaker RJ (2005) Global models for predicting woody plant richness from climate: development and evaluation. Ecology 86(9):2263-2277

70. Dumbrell AJ, Nelson M, Helgason T, Dytham C, Fitter AH (2010) Relative roles of niche and neutral processes in structuring a soil microbial community. ISME J 4(3):337-345

71. Chesson S (2000) Mechanisms of maintenance of species diversity. Annu Rev Ecol Syst 31:343-366

72. Chase JM, Leibold MA (2003) Ecological niches_-linking classical and contemporary approaches. University of Chicago Press, Chicago

73. Casamayor EO, Barberán A (2010) Global phylogenetic community structure and $\beta$-diversity patterns in surface bacterioplankton metacommunities. Aquat Microb Ecol 59:1-10

74. Zinger L, Amaral-Zettler LA, Fuhrman JA, Horner-Devine MC, Huse SM, Welch DBM, Martiny JB, Sogin M, Boetius A, Ramette A (2011) Global patterns of bacterial beta-diversity in seafloor and seawater ecosystems. PLoS One 6(9):e24570

75. Wardle DA, Bardgett RD, Klironomos JN, Setälä H, Van Der Putten WH, Wall DH (2004) Ecological linkages between aboveground and belowground biota. Science 304(5677):1629-1633

76. Van Der Gast CJ, Ager D, Lilley AK (2008) Temporal scaling of bacterial taxa is influenced by both stochastic and deterministic ecological factors. Environ Microbiol 10(6):1411-1418 